\title{
A Escala na Análise Geomorfológica
}

\author{
Heinz Charles Kohler \\ Pró-Reitoria de Pesquisa e de Pós-graduação - PUC/MG \\ Curso de Mestrado em Tratamento da Informação Espacial \\ charleskohler@uol.com.br
}

Artigo convidado recebido em 4 de setembro 2001

\begin{abstract}
RESUMO
Analisa o conceito da escala espaço-temporal na análise geomorfológica, em função de uma revisão bibliográfica da década de sessenta aos nossos dias. Destaca a importância de se adaptar a técnica de análise à escala de abordagem. Cita exemplos de trabalhos brasileiros, nas diferentes escalas espaço-temporais. Ressalta a importância da abordagem holística na geografia e em particular na geomorfologia, quando vista dentro de um geossistema integrado e dinâmico. Salienta a importância dos processos geo-bio-químicos, na base dos processos, responsáveis pela mutação dos diferentes cenários paisagísticos globais.
\end{abstract}

Palavras chaves: geomorfologia, geossistema, escala espaço-temporal, metodologia

\section{ABSTRACT}

It analyses concept of time-space scale in geomorphological analysis, based on a revision of the bibliography from the 1960 's onwards. It points out the importance of adapting the analysis technique to the scale of approach. It cites examples of Brazilian works, in different time-space scales. It emphatisizes the importance of the holistic approach in Geography and particularly in Geomorphology when it is viewed inside na integrated, dynamic geosystem. It calls attention to the importance of geo-bio-chemical processes, responsible for the mutation of different global landscape scenarios.

Keywords: geomorphology, geosystem, time-space scale, metodology.

\section{Introdução}

Em função da dinâmica dos processos geomorfológicos, que ocasionam constantes mutações nos cenários ambientais, a escala na análise geomorfológica deve ser compreendida como espaço-temporal. A representação de uma feição geomorfológica do relevo terrestre é feita em planta (representação gráfica da projeção horizontal), pelo cartógrafo, em uma folha de papel (duas dimensões). Para representarmos o volume (massa), do relevo, recorre-se à terceira dimensão através da curva de nível, a sucessão de pontos de mesma cota, uma isolinha altimétrica. A sucessão de curvas de nível, representam a grosso modo (não existe registro no intervalo da equidistância entre as curvas de nível), uma feição do relevo, como a forma de uma vertente: retilínea, côncava ou convexa. Já, para representarmos a dinâmica das formas do relevo, recorremos à sucessão de cenários temporais, os quais são registrados pelo cartógrafo, através de simbologia adequada. Estas quatro dimensões da abordagem do relevo terrestre é que tornam a geomorfologia um ramo da ciência geográfica, espacial e dinâmico, muitas vezes receitando remédios preventivos, de difícil venda, por suas características de longo prazo.

Visto que, a escala é apenas uma técnica de abordagem de um fenômeno espaço-temporal, iremos enfocar a escala da análise geomorfológica dentro de seu espaço e seu tempo.

Não pretendemos tratar do conceito espaço-temporal na concepção filosófica, neste sentido existe vasta bibliografia, iniciando-se com Aristóteles (Adler,1992), para o qual, tempo era quantidade de movimento, até ao atual e magnífico tratado de Hawking (1996) sobre a "Breve história do tempo". Apenas enfocaremos o espaço e o tempo na análise de diferentes cenários ambientais na concepção geomorfológica, onde o tempo é fundamental na construção e percepção da gênese e dinâmica do relevo de nosso planeta. Pretendemos trabalhar o conceito teórico-metodológico das escalas espaço-temporais, na aborda- 
gem geoambiental, no sentido verdadeiro, qual seja: o passado é a chave do presente e futuro.

Pretendemos abrir um grande leque bibliográfico, para possibilitar ampla margem de consulta e reflexão.

Tratam-se de reflexões sobre idéias amplamente divulgadas na literatura geomorfológica nacional e internacional. Destacam-se os seguintes trabalhos, abordando ampla revisão e discussão da bibliografia nacional e estrangeira: Ab'Sáber, 2000; 1998 (c/ref. bibliográfica); 1969; Abreu, 1978, 1982, 1983, 1985, 1986; Amorim, 1985, 1988, 1993; Barbosa et alii, 1983; Berry, 1972, 1975. Bertrand, 1968; Christofoletti, 1973, 1977, 1983, 1988; Coltrinari, 1982; Coltrinari \& Kohler,1987; Cruz,1985; Frazier,1981; Goudie, 2000; Goodey \& Gold, 1986; Kohler, 1979; Kohler \& Amorim, 1981; Langran,1993; Líbault, 1971; Marques, 1995; McCann \& Ford, 1996; Monteiro, 1984, 1988; 1991, 2000; Motoyama, 1977; Prigogine, 1985; Queiroz Neto \& Joumaux, 1978a, 1978b, 1978c; Ross, 1992; Silva, 1984; Sotchava, 1972, 1977; Tricart, 1977, 1979; Troll, 1950; Xavier da Silva, 1995.

\section{Reflexões sobre a escala espaço-temporal em geomorfologia}

Segundo Joly (1977), a geomorfologia é o ramo da geografia física, que se ocupa com o estudo das formas do relevo terrestre, de sua gênese, de sua evolução no tempo e de suas relações dentro do espaço.

Partindo do princípio, segundo o qual, determinado volume (medida do espaço ocupado por um sólido) só pode ocupar determinado espaço, em determinado tempo, a alteração do tempo imprime a noção de movimento, que será responsável pela dinâmica e evolução deste volume. Este, por sua vez, depende da escala da observação espacial e temporal.

Quanto menor a escala espacial de observação de um fenômeno geomorfológico contínuo (não catastrófico), mais lenta é sua transformação (dinâmica) e a reciproca é verdadeira. A deriva continental (pequena escala) é medida em milímetros /ano. Já a evolução de uma voçoroca (grande escala) é medida em metros/ano e a evolução de um sulco num paredão calcário (lapiás) em milímetros / minuto.

Por outro lado, quanto menor a escala espacial do fenômeno geomorfológico estudado, maior a influência dos processos endógenos (estrutura geológica) e mais regredimos na escala temporal (Cretáceo), (e a recíproca também é verdadeira). Quanto maior a escala espacial do fenômeno geomorfológico estudado, maior a influência dos processos exógenos (clima) e estamos, na escala temporal, mais próximo do atual (Holoceno).
O estudo da compartimentação do relevo do Brasil associa-se às grandes unidades geológico-estruturais da Plataforma Continental Sul Americana, elaboradas durante e após a reativação Mesozóica (Sul Atlanticana, Schobenhaus, 1984). Já o aprofundamento de um lapiás associa-se ao processo de dissolução que remonta às útimas chuvas.

Thombury (1960) em seus nove conceitos fundamentais da geomorfologia, estima que, poucas feições topográficas terrestres são mais velhas que o Terciário, e a maioria não seriam mais velhas do que o Pleistoceno. Lembra ainda que as estruturas geológicas são bem mais antigas que as feições geomorfológicas.

Schumm (1985) classifica os fenômenos geomorfológicos segundo a escala temporal em Mega, Meso, Micro e Não-eventos. Dependendo da escala espacial do fenômeno, os Megaeventos podem ocorrer durante 10 milhões de anos (Orogênese), 100.000 anos (glaciação continental), 100 anos (avulsão de um rio), 10 anos (mudança ou corte de um meandro), 1 ano (evolução de uma voçoroca), 1 dia (escorregamentos, rilling). Segundo o mesmo autor, um Megaevento, durante um curto período, pode tomar-se um Não-evento, quando seus efeitos são obliterados. A ruptura de um meandro, por exemplo, que ocasiona uma mudança dramática no Padrão de drenagem, tomando-se um Não-evento, é indetectável após 100.000 anos. A dimensão do evento aumenta com o tempo, e o tempo necessário para o seu desenvolvimento também cresce.

A escala de estudo de um relevo, irá determinar as estratégias e técnicas de abordagem da análise geomorfológica. Numa escala espacial pequena ultiliza-se, por exemplo, imagens de satélites, já numa escala grande faz-se uso das fotografias aéreas. A noção de escala é fundamental na cartografia geomorfológica (Demek, 1972, Demek \& Embleton \& KugIer, 1982; Spoene-mann \& Lehrmeister, 1985).

Kugler (1982), salienta a importância da escala no mapeamento geomorfológico, em função da mudança de conteúdo. Estabelece os limites abaixo das escalas de 1:100.000 (grande escala); 1:500.000 ( média escala) e 1:1.000.000 (pequena escala). Enquanto cartas de grande escala permitem mapear pequenos relevos, os mapas de pequena escala permitem mapear a base morfoestrutural e variações climatofaciais dos relevos de grandes espaços.

O trabalho de Cailleux \& Tricart (1956), amplamente divulgado no Departamento de Geografia da USP na década de 60, representa o marco inicial da utilização de uma escala espaço-temporal para fundamentar as pesquisas geomorfológicas. Os autores cruzam critérios espaciais e temporais, obtendo uma classificação taxonômica das formas do relevo (Tab. 1), base- 
ada num princípio dinâmico e outro dimensional. Fundamentam os princípios que ajudam a sistematizar os conhecimentos geomorfológicos em: 1 . A oposição de natureza dialética entre forças internas e externas; 2. 0 princípio da zonalidade, voltado essencialmente à dinâmica externa; 3 . A noção de evolução; 4. A ação do homem. Foi um trabalho precoce, uma vez que Tricart, na época não acreditava na Teoria da Deriva Continental. Apesar das acertadas críticas de Abreu (1986), principalmente quanto a supervalorização da escala em detrimento de sua essência, trata-se de um marco na sistematização da geomorfologia. A escola russa introduz os conceitos de morfoestrutura e morfoescultura, na classificação do relevo terrestre (Mescerjakov,1968), e a escola francesa a ótica geossistêmica da paisagem, proposta por Bertrand (1968), retomando os trabalhos pioneiros sobre geossistemas, vide Soctchawa (1972).

Amorim (1985) salienta que a linha de pesquisa de Bertrand (1968) e de Taillefer (1972) "_retoma um tema tradicional da prática geográfica - paisagem e lhe confere um suporte teórico atual." Mais adiante, o mesmo autor preconiza "... a abordagem que denominam global, na qual "a ênfase seria colocada não sobre tal ou qual elemento, mas sobre as relações que os unem. Se, em um espaço qualquer, um mesmo sistema de relações existe, poder-se-ão definir tipos de paisagens caracterizadas por sistemas de relações." Desse modo, o encaminhamento meto-dológico proposto para a nova análise das paisagens poderia ser resumido pelas seguintes demarches:

* definição dos conjuntos geográficos, isto é, das unidades isomorfas em função da escala: geotopo, geofacies, geossistema, região natural;

* análise da natureza e do significado das descontinuidades que separam esses conjuntos;

* estudos de relações dinâmicas dos conjuntos, em particular em função de seu tamanho;

* identificação espacial: os mosaicos dos conjuntos e os gradientes naturais.

Segundo Amorim (1985): "Essa ciência da paisagem se situa, no dizer de seus praticantes, no domínio interdisciplinar da confluência entre a Geografia e a Ecologia." A Tabela 2 exemplifica as Unidades de compartimentação da paisagem segundo George Bertrand. Não é necessário frisar, a importância da noção de escala, nessa concepção de compartimentação dos relevos terrestres.

Para finalizar estas reflexões, sobre a escala de análise dos fenômenos geomorfológicos, Schumm, (1985) resume "...a escala é muito importante na aplicação de uma abordagem analógica - extrapolativa. Quanto mais longo for o espaço de tempo e maior a área, menos precisa serão as previsões ou pós-visões, para o futuro ou passado, baseadas sobre o presente". Podemos facilmente classificar os relevos segundo as unidades de paisagem de Bertrand (Tab.2) e iremos confirmar a afirmação acima (Schumm, 1985).

\section{Exemplos da análise geomorfológica em pequena, média e grande escala}

A melhor maneira de se representar uma análise geomorfológica é através da cartografia. São os mapas, a melhor ferramenta do geógrafo. Um mapa geomorfológico, com uma boa resolução cartográfica, é um instrumento de leitura univer-sal, acessível a qualquer profissional, mesmo não geógrafo. Deve conter os referenciais geomorfoló-gicos, georeferênciados no espaço e no tempo. Deve contemplar as quatro dimensões acima descritas.

Como exemplo brasileiro, de uma representação em pequena escala, devemos ressaltar, o mapa pioneiro de Ab'Sáber (1970) das Áreas Nucleares dos Domínios Morfoclimáticos Brasileiros, sem dúvidas a maior contribuição daquele autor a geomorfologia brasileira. Mais tarde o mesmo autor (Ab'Sáber,1977), introduz o conceito de barreiras biogeográficas e define a área dos pantanais. Talvez pudéssemos ainda locar as áreas cársticas, uma vez que a porção ocupada por estes relevos, perfazem quase $10 \%$ do território nacional, localizados nas Bacias dos rios São Francisco e Paraguai. Sobre as rochas carbonáticas, desenvolvem-se os relevos cársticos que, independente do domínio morfoclimático abriga inclusões de uma mata semi-deciducifólio ou Floresta Mesófila Estacional. Na região de Lagoa Santa - MG, esta mata apresenta espécies da caatinga, como as cactáceas, constituindo palimpsestos de um paleoclima pretérito.

Ainda como exemplos de mapeamentos geomorfológicos, em pequena escala, devemos citar os trabalhos do Projeto RADAMBRASIL (Argento, 2000), o Mapa Geomorfológico do Estado da Bahia (1:1.000.000) de Silva (1980) e o Mapa Pedogeoquímico do Estado da Bahia de Nascimento (1986).

Destacam-se ainda os trabalhos pioneiros de mapeamentos do "Tipos Morfogenéticos" baseados na intensidade dos processos geoquímicos e geofísicos responsáveis pela elaboração do relevo, de Moreira \& Camelier (1977) e da compartimen- 


\begin{tabular}{|c|c|c|c|c|c|}
\hline $\begin{array}{l}\text { Ordem } \\
\mathrm{G}\end{array}$ & $\begin{array}{l}\text { Unidade } \\
\text { de } \\
\text { superfície }\end{array}$ & $\begin{array}{l}\text { Características das } \\
\text { Unidades-Exemplos }\end{array}$ & $\begin{array}{l}\text { Unidades Climáticas } \\
\text { correspondentes }\end{array}$ & $\begin{array}{l}\text { Mecanismos genéticos } \\
\text { comandando o relevo }\end{array}$ & $\begin{array}{c}\text { Ordem de } \\
\text { grandeza de } \\
\text { permanência } \mathrm{T} /\end{array}$ \\
\hline I & $10^{7}$ & $\begin{array}{c}\text { Continentes, Bacias } \\
\text { oceânicas (configuração do } \\
\text { globo) }\end{array}$ & $\begin{array}{l}\text { Grandes conjuntos zonais, } \\
\text { comandados por fatores } \\
\text { astronômicos }\end{array}$ & $\begin{array}{l}\text { Diferenciação da crosta } \\
\text { terrestre, SIAL e SIMA }\end{array}$ & $10^{9}$ anos \\
\hline II & $10^{6}$ & $\begin{array}{c}\text { Grandes conjuntos } \\
\text { estruturais (Escudo } \\
\text { Escandinavo, Tetis, B. do } \\
\text { Congo) }\end{array}$ & $\begin{array}{l}\text { Grandes tipos de clima } \\
\text { (interferência de influências } \\
\text { geográficas com fatores } \\
\text { astronômicos) }\end{array}$ & $\begin{array}{l}\text { Movimento da crosta terrestre } \\
\text { como a formação dos } \\
\text { geosinclinais, influências } \\
\text { climáticas sobre a dissecação }\end{array}$ & $10^{8}$ anos \\
\hline III & $10^{4}$ & $\begin{array}{l}\text { Grandes unidades } \\
\text { estruturais (Bacia de Paris, } \\
\text { Jura, Maciço Central) }\end{array}$ & $\begin{array}{c}\text { Feições nos tipos de clima, mas } \\
\text { sem grande importância para a } \\
\text { dissecação }\end{array}$ & $\begin{array}{l}\text { Unidades tectônicas tendo } \\
\text { ligação com a Paleogeografia. } \\
\text { Velocidade de dissecação } \\
\text { influenciada pela litologia }\end{array}$ & $10^{7}$ anos \\
\hline IV & $10^{2}$ & $\begin{array}{c}\text { Unidades tectônicas } \\
\text { elementares: maciços } \\
\text { montanhosos, horsts, fossas }\end{array}$ & $\begin{array}{c}\underset{\text { Climas regionais de influência }}{\text { geográfica sobretudo nas }} \\
\text { regiões montanhosas }\end{array}$ & $\begin{array}{c}\text { Influência predominante da } \\
\text { tectônica, secundária da } \\
\text { litologia }\end{array}$ & \\
\hline
\end{tabular}

\section{SOLEIRA DE COMPENSAÇÃO ISOSTÁTICA}

\begin{tabular}{|c|c|c|c|c|c|}
\hline V & 10 & $\begin{array}{l}\text { Acidentes tectônicos: } \\
\text { anticlinal, sinclinal, mont } \\
\text { etc. }\end{array}$ & $\begin{array}{c}\text { Climas locais influenciados pela } \\
\text { disposição do relevo }\end{array}$ & $\begin{array}{c}\text { Predominância da Litologia e } \\
\text { Tectostatica. Influências } \\
\text { estruturais clássicas }\end{array}$ & $\begin{array}{l}10^{7} \text { anos } \\
10^{6} \text { anos }\end{array}$ \\
\hline VI & $10^{-2}$ & $\begin{array}{l}\text { Formas de relevo: crista, } \\
\text { terraço, moraina, cone de } \\
\text { dejeção etc. }\end{array}$ & $\begin{array}{l}\text { Mesoclima diretamente ligado a } \\
\text { forma (nicho de nivação, por } \\
\text { exemplo) }\end{array}$ & $\begin{array}{c}\text { Predominância do fator } \\
\text { morfodinâmico influenciado } \\
\text { pela litologia }\end{array}$ & $10^{4}$ anos \\
\hline VII & $10^{-6}$ & $\begin{array}{l}\text { Microformas: lentes de } \\
\text { solifluxão, solos poligonais, } \\
\text { ravinas }\end{array}$ & $\begin{array}{c}\text { Microclima diretamente ligado } \\
\text { à forma por autocatalise (ex: } \\
\text { lapiás) }\end{array}$ & $\begin{array}{c}\text { Microclima diretamente ligado } \\
\text { à forma por autocatalise (ex: } \\
\text { lapiás) }\end{array}$ & $10^{2}$ anos \\
\hline VIII & $10^{-8}$ & $\begin{array}{l}\text { Feições microscópicas: } \\
\text { detalhes de corrosão, de } \\
\text { polimento etc. }\end{array}$ & Microambiente & $\begin{array}{l}\text { Influência da dinâmica e da } \\
\text { textura da rocha }\end{array}$ & \\
\hline
\end{tabular}


Kohler, H. C. / Revista Brasileira de Geomorfologia, volume 2, nº1 (2001) 21-33

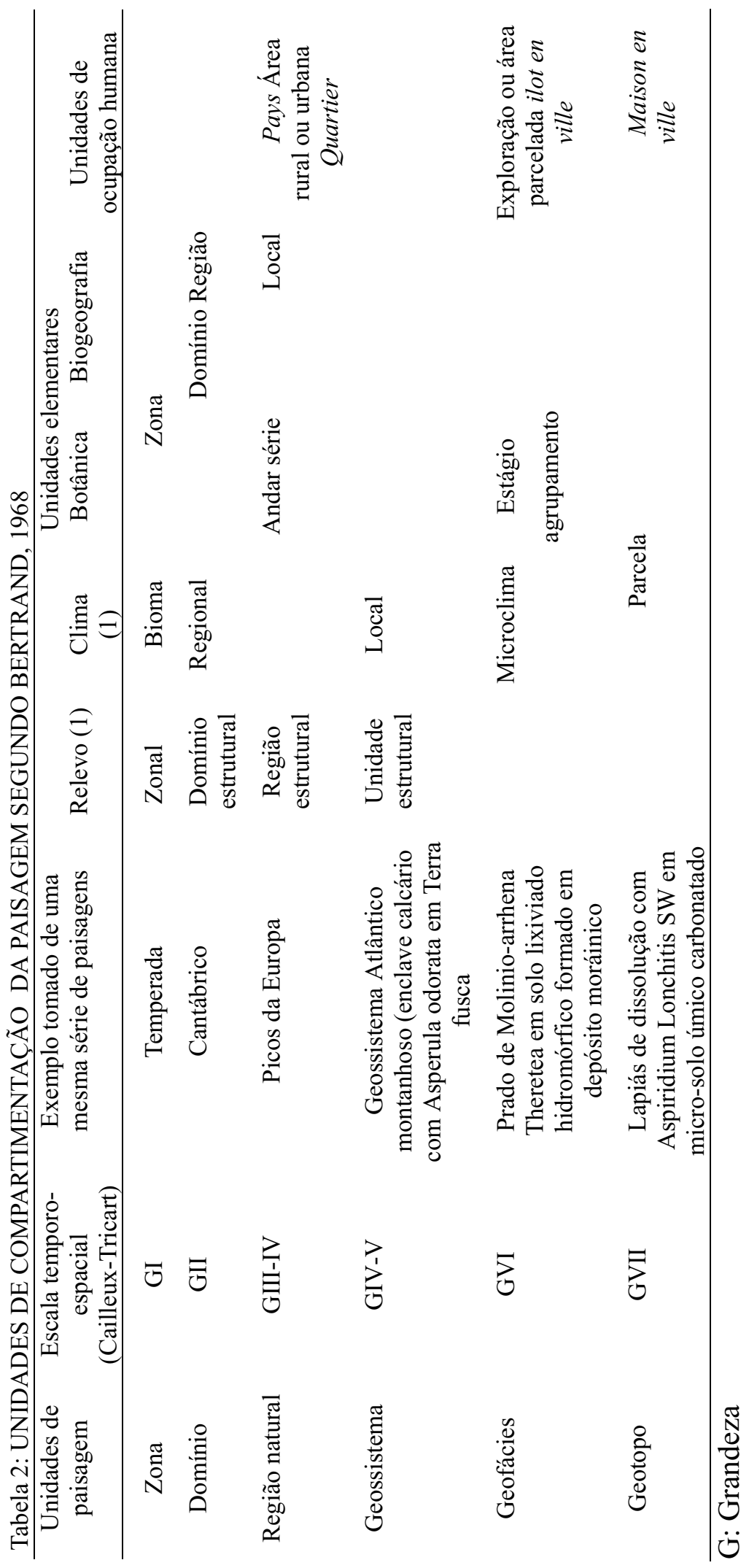


tação dos "Tipos de Morfogenêse em Minas Gerais" de Barbosa (1978).

Em grande e média escala destacam-se os trabalhos pioneiros, das cartas do modelado e das formações superficiais do Vale do Parateí (1: 25.000), São Pedro (1:50.000) e de Marília (1:100.000), elaborados em convênio entre o Laboratório de Pedologia e Sedimentologia do Instituto de Geografia e do Departamento de Geografia da FFLCH da USP e Centre de Géomorphologie du CNRS - Caen/França, sob a coordenação do J.P. Queiroz Neto e A. Journaux, (Instituto de Geografia, 1978 a,b,c,d; Coltrinari, 1982).

Em 1981, foi publicada pelo Instituto de Geociências Aplicadas da Secretaria de Estado de Ciências e Tecnologia do Estado de Minas Gerais, o primeiro Mapa do Meio Ambiente e sua Dinâmica do Município de Itauna (1:50.000 com encarte de 1:25.000), segundo base metodológica elaborada pelo Prof. A. Journaux, da União Geográfica Internacional (Kohler \& Amorim, 1981). A Companhia de Tecnologia de Saneamento Ambiental (CETESB) do Estado de São Paulo, publica a Carta do Meio Ambiente e sua Dinâmica da Baixada Santista/SP, segundo a mesma metodologia do Prof A. Journaux (CETESB, 1985).

O Instituto de Pesquisa e Tecnologia (IPT) do Estado de São Paulo, elabora Carta Geotécnica dos Morros de Santos e São Vicente (IPT,1975). Inúmeras cartas temáticas, enfocando a análise ambiental (Geoecológica), foram elaboradas pela iniciativa privada, de divulgação restrita.

Em grande escala, destacam-se os trabalhos elaborados, segundo metodologia desenvolvida para o levantamento da estrutura pedológica (Boulet, 1978; Castro, 1989; Barros, 1985; Ruellan et.al., 1989; Ferreira,1997; Manfredini \& Queiroz Neto, 1993; Salomão, 1994).

Um evento seqüencial, da aplicação simultânea da análise geomorfológica em pequena, média e grande escalas, pode ser avaliado a partir dos trabalhos de Kohler, (1989); Parizzi (1993) e Parizzi et.al. (1998) onde parte-se de uma compartimentção geológica - geomorfológica na escala aproximada de 1:500.000, para chegar ao nível da análise polínica dos sedimentos lacustres da Lagoa Santa.

(Kohler, 1989)

1:500.000 Compartimentação Geomorfológica da Região de Belo Horizonte - Lagoa Santa / MG.
(Região Natural $=$ Borda meridional do Planalto Central Brasileiro)

1. Bacia do Rio das Velhas

1. 1. Serra do Curral

1.2 Depressão de Belo Horizonte

1.3. Depressão de Vespasiano

1.4. Planalto de Lagoa Santa

1.4. 1. Carste (alto índice de carstificação)

1.4.2. Carste (baixo índice de carstificação)

1. 5. Planalto de Neves

1.6. Planalto de Cordisburgo

2. Bacia do Rio Paraopeba

2. 1. Divisor de águas

Critérios de compartimentação: geológico-estrutural, geomorfológico. (Predominam os processos endógenos).

Idade: Orogênese Minas (Mesozóico, 245 a 65 milhões de anos)

\section{(Kohler, 1989)}

1: 50.000 Compartimentação do Relevo Cárstico do Planalto de Lagoa Santa

(Geossistema do Planalto de Lagoa Santa, enclave cárstico).

1. Carste alto índice de dissolução

1.1. Desfiladeiros, abismos, altos paredões $(>40 \mathrm{~m})$

1.2. Cinturão de ouvalas

1.3. Planalto de dolinas

1.4. Poliés

2. Carste baixo índice de dissolução

2. 1. Serra dos Ferradores (Superfície Sul Americana). Carste encoberto.

2.2. Relevos de Lagoa Santa

2.3. Relevos a oeste do Ribeirão do Jaque

2.4. Relevos na margem direita do Rio das Velhas

2.5. Relevos ao longo do Ribeirão da Mata

Critérios: geomorfologia cárstica, dissolução (climático). Predominam os processos exógenos. Pleistoceno.

\section{(Parizzi, 1993)}

1:20.000 Carta Morfológica da bacia de Lagoa Santa (Geofacie: a Lagoa Santa, sedimentos lacustres).

1. Sistema lacustre - fluvial

2. Sistema de vertentes

2. 1. Formas erosivas 


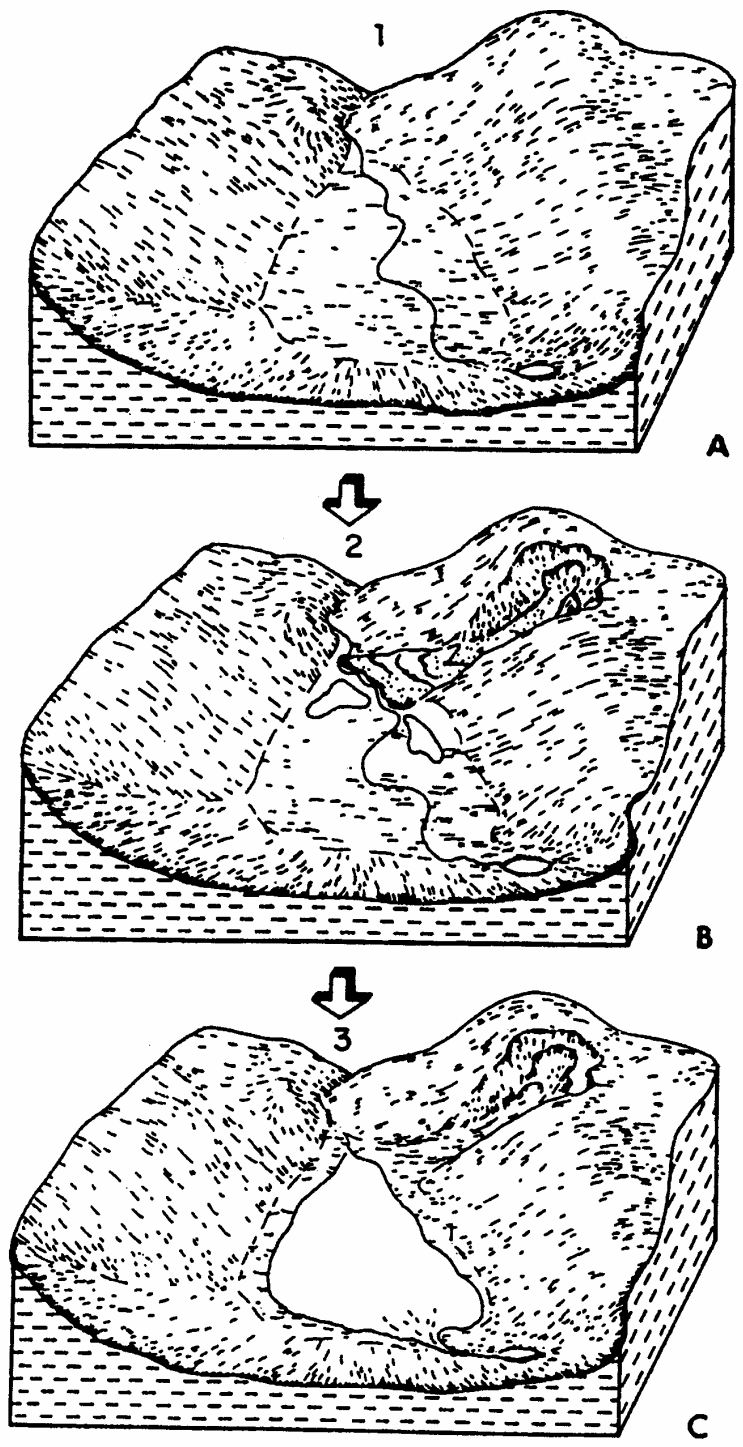

Figura 1 (Parizzi,1993).

\section{COLUNA BIOLITOCRONOESTRAFIGRÁFICA}

4.1 Testemunho dos sedimentos lacustres da Lagoa Santa (Geotopo: Matéria orgânica, C 14, polens).

Parizzi \& Kohler \& Salgado-Laboriau (1996), estabelecem a gênese da lagoa, em função de estudos geomorfológicos e palinológicos: " Os dados revelam a existência, no passado, de um intenso deslizamento de terra ocorrido ao longo da encosta do Morro do Cruzeiro, que teria conduzido grande quantidade de sedimentos de encontro ao Córrego Bebedouro provocando uma barragem do seu curso e conseqüente inundação da depressão (Fig. 2). As evidências desse processo são averiguadas pelas características morfológicas da bacia. A elevada inclinação dessa vertente (899m e declive $12 \%$ ) facilitou a desestabilização e o deslizamento do material do topo até a sua base gerando um depósito de mais de $6 \mathrm{~m}$ de espessura, comprovado pela tradagem, coincidente com a profundidade da lagoa. Esse material foi 


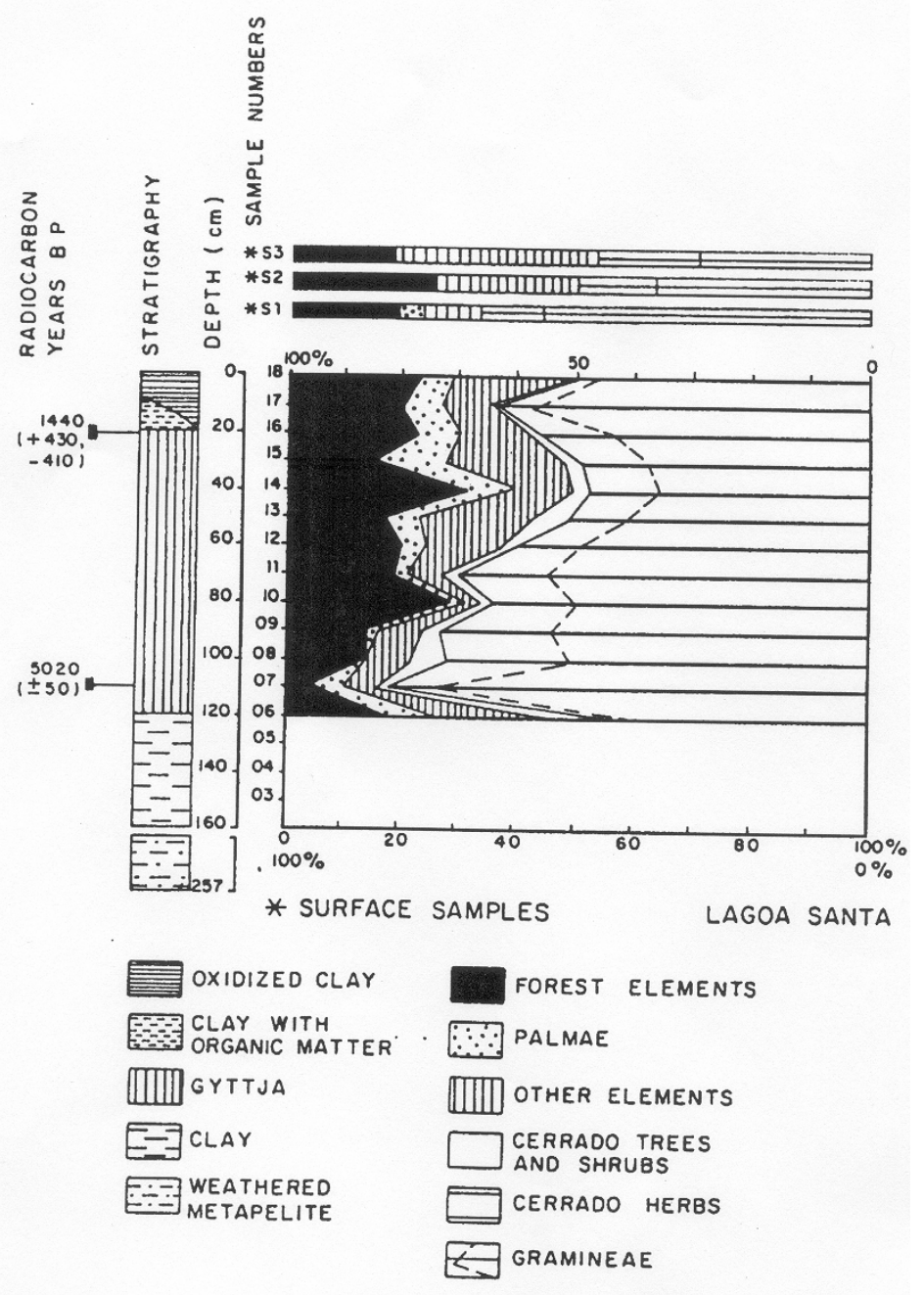

Figura 2. Bertrand, 1968.

aprisionado na estreita várzea do Córrego Bebedouro formando a barragem natural. Análises palinológicas (Parizzi, 1993) de um testemunho de $2,57 \mathrm{~m}$ dos sedimentos de fundo da lagoa revelaram uma idade de aproximadamente 6200 anos A.P. para a origem da lagoa. A predominância do esporo Lycopodium cernuum, nos primeiros níveis do testemunho da base para o topo, ressalta a hipótese da ocorrência do deslizamento de terra no passado; uma vez que esta espécie é conhecida como sendo de regeneração de áreas onde processos desse tipo ocorrera.

Entre cerca 6.200 a 5.000 anos A.P., o pântano foi substituído pela lagoa perene. Um mosaico de mata e cerrado cobria a região em volta da lagoa e o clima era de duas estações, com estação seca prolongada, semelhante ao atual.

Entre 3.000 e 1.800 anos A.P., o conjunto palinológico indica uma flora rica e diversificada que mostra diferentes tipos de floresta e que um cerrado arbóreo mais denso crescia na região. $\mathrm{O}$ clima era mais úmido que o atual.

A partir de 1.440 anos A.P., a umidade diminuiu e o clima chegou aos valores atuais. "Os últimos $20 \mathrm{~cm}$ do testemunho, abaixo da interface água-sedimento, marcam a passagem da argila orgânica para argila oxidada misturada ao sedimento lacustre."

\section{Extrapolação por analogia para as escalas menores}

Os dados obtidos foram extrapolados para escalas médias e menores, permitindo uma avaliação da dinâmica ambiental regional, dos últimos 6.000 anos à elaboração da Superfície Sul Americana no Plioceno.

\section{E agora? Na aurora do ano 2000!}


Berry (1975) postula: " ... o futurólogo ao projetar imagens do futuro, pode perfeitamente ser influente em produzir aquele futuro indicando uma cadeia de alternativas que o povo pode se esforçar para conseguir ou evitar, a mudança social mais importante de nosso tempo é a difusão da tomada de consciência de que temos capaci-dade de lutar e deliberadamente planificar a pró-pria mudança". Dificilmente podemos concordar com Berry (op. cit.), em planejar mudanças nos processos endógenos e exógenos, responsáveis pela dinâmica ambiental, salvo medidas monstru-osas e catastróficas para a raça humana e de todos seres vivos, de uma explosão nuclear de magni-tude a abalar a estrutura endógena global, ou da alteração das correntes marítimas, pelo homem, ocasionando mudanças na circulação atmosférica terrestre. As mudanças globais ocasionadas pelo El Niño, por exemplo, tiveram sua origem ligada a entrada de grandes massas de águas, de alto grau geotérmico (quentes), através de fendas geotectônicas localizadas na fossa submarina do Pacífico nas costas do Equador, ligadas ao ocean floor spreading, que segundo alguns geofísicos tiveram inicio há quatro bilhões de anos.

Acreditamos que a geomorfologia deverá ingressar no ano 2.000, como uma ciência num estado de relativa calma (não paradigmático). Não é prevista uma revolução estrutural da geomorfologia no sentido de Kuhn (1962). Ao contrário de Horgan (1996), autor do controvertido livro The End of Science, que concluiu ter acabado a época das grandes descobertas, acreditamos existir muito a ser desvendado no campo da geomorfologia. Enormes lacunas no levantamento geomorfológico global, principalmente no Brasil, ao lado das pesquisas em grande escala, de cunho interdisciplinar, deverão redirecionar os processos responsáveis pela gênese e dinâmica das paisagens atuais, permitindo uma gestão mais racional do espaço.

Neste sentido, vivenciamos o paradigma que separa a obsessão das superfícies de aplainamento dos anos 50, no Brasil (Monteiro,1991), das novas teorias geoquímicas de elaboração destas superfícies, em meio intertropical, por aprofundamento geoquímico (enfoncement géochimique, Tardy, 1993), da nossa década. Deve ser lembrado que o termo etchingsurface (superfície de corrosão), portanto predominan-temente química, data da década de 30 (Wayland, 1933), mas nunca foi utilizada entre nós, nem de maneira empírica, salvo a referência conceitual de Thomas (1994; 1974; 1968) e Novaes Pinto (1988). Ressaltamos então, a importância da pesquisa em grande escala, aliada às novas técnicas da geoquímica, micromorfologia, análise polínica, datações radiométricas, e sobre tudo o tratamento da informação geográfica através da interpretação seqüencial das imagens de satélite LANDSAT 7 e
IKONOS (Halls, 2001) e da aplicação do Sistema de Informação Geográfico (Langran, 1992).

A teoria espaço-temporal, deverá refinarse cada vez mais em direção das pequenas escalas, localizadas no passado, através da extrapolação de analogias descobertas em pequenos espaços (grande escala), bem como, através da aplicação de novas técnicas das ciências exatas, biológicas e da terra.

A dimensão fractal, introduzida por Mandelbrot (1967; 1975a; 1975b), foi tida por alguns como a descoberta do século, comparável à teoria quântica, teoria geral da relatividade e ao desenvolvimento do modelo da estrutura do DNA (Gao \& Xia, 1996) e poderia representar um novo paradigma ou, pelo menos, uma nova orientação para a geomorfologia.

Segundo Christofoletti \& Christofoletti (1995): "A abordagem das fractais possui amplo campo de aplicação nos estudos sobre o formato das ocorrências dos objetos analisados em Geociências, como técnica para se compreender a disposição geométrica dessas estruturas espaciais. A fractal é uma representação geométrica na qual um motivo idêntico repete-se constantemente com a diferenciação (aumento ou diminuição) da escala. A configuração geométrica repetitiva fornece-lhe a característica da auto-similaridade, enquanto a conservação da similaridade, nas diversas escalas, concede-lhe o aspecto da invariância escalar."

Gleick (1990) em seu didático livro sobre o Caos esclarece a invariância escalar através do seguinte exemplo: "Uma forma geométrica tem uma escala, um tamanho característico. Para Mandelbrot, a arte que satisfaz não tem escala, no sentido de que contém elementos importantes de todos os tamanhos. Ele contrapõe ao Edifício Seagram, a arquitetura do estilo Beaux-Arts, com suas esculturas e gárgulas, suas pedras angulares e jambas, suas janelas decoradas com arabescos, suas cornijas encimadas, de calhas e revestidas de dentículos. Um exemplo do estilo Beaux-Arts como a Ópera de Paris não tem escala porque tem todas as escalas. Ao ver o edifício de qualquer distância, o observador encontra detalhes que atraem os olhos. A composição muda quando ele se aproxima, e novos elementos da estrutura entram em função".

A dimensão fractal é um número real que mede o grau da irregularidade de um objeto. $\mathrm{Na}$ geometria euclidiana clássica um ponto tem a dimensão 0 , uma linha a dimensão 1 e um plano a dimensão 2. A dimensão fractal pode ser qualquer número entre 1 e 2 para uma linha e 2 e 3 para uma área, dependendo de sua complexidade. A dimensão 2 representa, na geometria fractal, uma linha tão curva e plana que engloba todo um espaço bidimensional. Assim como a dimensão 
fractal de uma rede de canais está próximo a 2 , pois uma rede como um todo engloba um espaço (Gao \& Ma, 1996).

A geometria fractal, pode representar os diferentes graus de rugosidade de um relevo (energia do relevo), através de um indicador quantitativo da complexidade topográfica, mas apresenta sérias limitações quanto aos estudos geomorfológicos relacionados a processos, pois não existe uma proporção de um para um, entre a dimensão fractal e os processos (Gao \& Ma, 1996). Um relevo, na maioria das vezes, foi elaborado por processos policíclicos, modelado por diferentes processos em diferentes escalas temporais.

A teoria fractal, com seus algoritmos, não constituiu um novo paradigma para a geomorfologia, pelo menos não para espaços tridimensionais.

Para finalizar, devemos ressaltar ainda que a abordagem holística na geografia, e em particular na geomorfologia, sempre existiu e deverá ser incrementada no futuro, através de uma análise interdisciplinar. A nova consciência ambientalista deverá alcançar os países em desenvolvimento, abrindo o campo de atuação do geógrafo que, no entanto, deverá competir e se associar aos arquitetos, engenheiros (sanitarista e ambiental), geólogos, biólogos, agrônomos, entre outros, tendo como munição, a classificação espaço-temporal, de suas diferentes paisagens, em suas diferentes escalas.

\section{Bibliografia}

Abreu, A.A. - 1978 - Considerações a respeito de uma epistemologia da geomorfologia. Boletim Paulista de Geografia. São Paulo. (55):125-135.

Abreu, A.A. - 1982 - Análise Geomorfológica: Reflexão e Aplicação. São Paulo. Dep. Geografia USP.

Abreu, A.A. - 1983 - A teoria geomorfológica e sua edificação. Rev. Instituto Geológico. São Paulo, (4):5-23.

Abreu, A.A. - 1985 - Significado e propriedades do relevo na organização do espaço. Boletim de Geografia Teorética. Rio Claro (15):154-162.

Abreu, A.A. - 1986 - Considerações a respeito dos fundamentos conceituais das classificações geomorfológicas, utilizadas no Brasil. Boletim Paulista de Geografia. São Paulo (23): 49-59.

Ab'saber, A. N. - 2000 - Fundamentos da geomorfologia costeira do Brasil Atlântico inter e subtropical. Revista Brasileira de Geomorfologia, 1:27-43.

Ab'saber, A. N. - 1998 - Megageomorfologia do território brasileiro. In: CUNHA, S. B. e
GUERRA, A. T. J. (Org.). Geomorfologia do Brasil. Editora Bertrand Brasil. Rio de Janeiro. p.71-106.

Ab'saber, A. N. - 1971 - A organização natural das paisagens inter e subtropicais brasileiras. In. FERRI, M.G.(Org.) - III Simpósio sobre o cerrado. São Paulo. Ed. Edgard Blücher LTDA.. p.1-14.

Ab'saber, A. N. - 1977 - Os domínios morfoclimáticos da America do Sul. São Paulo. Geomorfologia . IGEOG-USP 52:1-21.

Ab'saber, A. N. - 1969 - Um conceito de geomorfologia a serviço das pesquisas sobre o quaternário. Geomorfologia. São Paulo. Instituto de Geografia USP, (19):1-23.

Adler, M.J. - 1992 - The works of Aristotle. Great Books of the Western World. Chicago. Encyclopaedia Britanica . Vol.II pp. 297302.

Amorim, O.B. - 1985 - Reflexões sobre as tendências Teórico-Metodológicas da Geografia. Belo Horizonte. Publicação Especial, Dep. de Geografia, IGC-UFMG. (2): $1-56$.

Amorim, O.B. - 1988 - As geografias universais e a passagem do milênio. Revista Geografia e Ensino. Belo Horizonte. Departamento de Geografia IGC-UFMG, 3 (9): 18-34.

Amorim, O.B. - 1993 - Las mas recientes reflexiones sobre Ia evolucion del pensamiento. Geográfico. Paisajes Geográficos. Quito. 13 (27):16-18.

Argento, M.S.F. - 1994- Mapeamento Geomorfológico. In: GUERRA, A. J. T. \& CUNHA, S. B. Geomorfologia uma atualização de bases e conceitos. Rio de Janeiro. Bertrand do Brasil pp.365-391.

Barbosa, G.V. - 1978 - A Área Da Lagoa Santa no Estado de Minas Gerais. São Paulo. Colóquio Interdisciplinar Franco-Brasileiro. IGEOG-FFLCH-USP 2:5-19.

Barbosa, G.V. \& Silva, T.C. \& Natali Filho,T. \& Del'arco, D. M. \& Costa, R. C. R. - 1983 Evolução da metodologia para mapeamen-to geomorfológico do projeto RADAM-BRASIL. Geociências. São Paulo (2):7- 20.

Barros, O.N.F. - 1985 - Análise estrutural e cartografia detalhada de solos em Marília, SP: ensaio metodológico. São Paulo, Departamento de Geografia, FFLCHUSP, (dissert. Mestrado), p 146.

Berry, B.J.L. - 1972 - Um paradigma para a geografia moderna. R Bras. Geog., Rio Janeiro, 34(3):3-13.

Berry, B.J.L. - 1975 - Mudança deliberada nos sistemas espaciais. Geografia e Planeja- 
mento. São Paulo. Instituto de Geografia USP, (21):1-25.

Bertrand, G. - 1968 - Paysage et géographie physique globale. Esquise méthodologique. - Rev. Géograph. des Pyrénées et du Sud-Ouest, 39(3):249-272. Trad. por 0. CRUZ in Caderno de Ciencias da Terra. São Paulo. Instituto de Geografia USP, (13) $\mathrm{pp} 27$.

Boulet, R. - 1978 - Toposéquence de sols tropicaux en Haute-Volta, Équilibre et déséquilibre pédobioclimatique. Paris. Mémoire ORSTOM 85:1-272.

Cailleux, A. \& Tricart,J. - 1956 - Le problème de la classification des faits géomorphologiques. Ann. de Géogr.,65:162 -186.

Castro, S.S. - 1989 - Sistemas de transformação pedológica em Marília: B latosólicos e B texturais. São Paulo. Departamento de Geografia - FFLCH-USP. (Tese de doutorado) p274.

Cetesb - 1985 - Mapa do Meio Ambiente e de sua dinâmica. Baixada Santista. 1:50.000. são Paulo. Secretaria de Obras e do Meio ambiente.

Christofoletti, A. - 1973 - Geomorfologia: defini ção e classificação. Boletim de Geografia Teorética. Rio Claro,3(5):39-45.

Christofoletti, A. - 1977 - As tendências atuais da geomorfologia no Brasil. Notícia Geomorfológica. Campinas, 17(33):35- 91.

Christofoletti, A. - 1983 - Mapeamentos geomor fológicos no Brasil. Geociências. Rio Claro, São Paulo,(2:)1-6.

Christofoletti, A. - 1988 - A potencialidade das abordagens sobre sistemas dinâmicos para os estudos geográficos: alerta para uma nova fase. Geografia. Rio Claro. 13 (26) 149-151.

Christofoletti, A. \& Christofoletti, A.L.H. - 1995 A abordagem fractal em geociências. Geociências. São Paulo, 14(1):227-264.

Coltrinari, L. - 1982 - Um exemplo de carta geomorfológica de detalhe: a carta do médio vale do Rio Parateí, SP (1:25.000). Orientação. São Paulo. (1):55-63.

Coltrinari, L. \& Kohler, H.C. - 1987 - O Quaternário continental brasileiro: estado da arte e perspectivas. I Congresso da ABEQUA. Anais. Porto Alegre, 27-36.

Cruz, O. - 1985 - A escala temporal-espacial nos estudos dos processos geomorfológicos. Geomorfologia. São Paulo. Instituto de Geografia-USP, (33); 1-6.

Demek, J. ed. - 1972 - Manual of detailed geomorphological mapping. Brno.

Demek, J. \& Embleton,C. \& Kuglerh. - 1982 Geomorphogische Kartierung in mittleren Massstaeben. Gotha. Haack,pp254.
Frazier, J.W. - 1981 - Geografia aplicada e pragmatismo. Geografia e Planejamento. São Paulo. Instituto de Geografia - USP, (36):1-12.

Ferreira, R.P.D. - 1997 - Solos e morfogênese em São Pedro - SP. São Paulo. Departamento de Geografia, FFLCH-USP. (tese de doutorado) p. 157.

Gao, J. \& Xia, Z. - 1996 - Fractal in physical geography. Progress in Physical Geography, 20 (2):178-191.

Gleick, J. - 1990 - Caos: a criação de uma nova ciência. Rio de Janeiro. Campus, pp 310.

Goodie, A. S. - 2000 - The integration of physical geography. Geographica Helvetica. 3:163-168.

Goodey, B. \& Gold, J. - 1986 - Geografia do comportamento e da percepção. Publicação Especial. Belo Horizonte. Departamento de Geografia IGC-UFMG, (3): $1-49$.

Halls, P. J. -2001 - Spacial information and the environment. London. Taylor \& Francis. pp. 284 .

Hawking, S. - 1988 - The illustrated brief history of time. New York. Banttan. pp.248.

Hawking, S. - 1996 - The illustrated a brief history of time. New York. Bantam.pp 238.

Horgan, J. - 1996 - The end of science. New York. Addison Wesley,pp.309.

Instituto de Geografia e Departamento de Geografia - FFLCH-USP - 1978a - Carta do modelado e das Formações Superficiais do médio vale do Rio Parateí - SP. 1:25.000. Sedimentologia e Pedologia 9:1-35.

-1978 b - Carta Geomorfológica do vale do Rio do Peixe em Marília - SP. 1:100.000. Sedimentologia e Pedologia 10:1-22.

-1978c - Carta de Formações Superficiais do vale do Rio do Peixe em Marília - SP. 1:100.000.Sedimentologia e Pedologia. 11:1-18.

-1978d - Carta Geomorfológica de São Pedro - SP. Sedimentologia e Pedologia 12:1-33.

Institito de Pesquisa e Tecnologia do Estado de São Paulo - 1975 - Carta geotécnica dos morros de Santos e São Vicente. Escala aproximada 1:15.000.

Joly, F. - 1977 - Point de vue sur la géomorphologie. Annales de Géographie. 86(477): 522-541.

Kohler, H.C. - 1979 - Região de Igaratá: reflexões sobre metodologia e técnicas aplicadas à análise geomorfológica. São Paulo. De- 
partamento de Geografia, FFLCH-USP (dissertação de mestrado).

Kohler, H.C. - 1989 - Geomorfologia cárstica na região de Lagoa Santa-MG. São Paulo. FFLCH USP. Departamento de Geografia. pp. 113 (tese de doutoramento).

Kohler, H.C. \& Amorim, O.B. (coord.) - 1981 Carta do meio ambiente e sua dinâmica no Município de Itauna - MG. Belo Horizonte. Instituto de Geociências Aplicadas.

Kugler, H. - 1982 - Gegenstand und Arbeitsrichtungen. In: (DEMEK, J. \& EMBLETON, C. \& KUGLER edts.- 1982 Geomorphologische Kartierung en mittleren Massstaeben. Gotha, Haak.) 12 -41 .

Kuhn, T. S. - 1975 - A estrutura das revoluções científicas. São Paulo. Perspectiva.

Langran, G. - 1993 - Time in Geographic Information System. London. Taylor \& Francis. Pp189.

Libault, A. - 1971 - Os quatro níveis da pesquisa geográfica. Métodos em Questão. São Paulo. Instituto de Geografia - USP, (1): $1-14$.

McCann \& Ford, D. - 1996 - Geomorphology sans frontières.New York. John Wiley \& Sons. pp. 245.

Mandelbrot, B. - 1967 - How long is the coastline of Britain? Statistical self-similarity and fractal dimension. Science. 5 6: 63 6-63 8.

Mandelbrot, B. - 1977 a - The fractal geometry of nature. New York. Freeman.

Mandelbrot, B. - 1977 b - Fractals: form, change and dimension. San Francisco. Freeman.

Manfredini, S. \& Queiroz Neto - 1993 - Comportamento hídrico de sistema de transformação lateral B latossólico/B textural em Marília -SP. $24^{\circ}$ Congresso Bras Ci. Solo Goiânia, Resumos, 1:91-92.

Marques, J.S. - 1994 - Ciência geomorfológica. (In: GUERRA, A.J.T. \& CUNHA, S.B. Geomorfologia: uma atualização de bases e conceitos. Rio de Janeiro. Bertrand Brasil, 1994):23-50 .

Mescerjakov, J.P. - 1968 - Les concepts de morphostructure et de morphosculpture: Ann. de Géogr. 423:539-552.

Monteiro. C.A.F. - 2000 - Geossistemas: a história de uma procura. São Paulo. Contexto.

Monteiro, C.A.F. - 1991 - Clima e exepcionalismo. Florianópolis. Ed. da UFSC, pp.241.

Monteiro. C.A.F. - 1988 - Travessia da crise (tendências atuais da geografia). Revista Bras. de Geografia. IBGE, 50:127-150

Monteiro, C.A.F. - 1984 - Geografia e ambiente. Orientação. São Paulo, (5): 19-27.
Moreira, A.A.N. \& Camelier,C. - 1977 - Relevo in Geografia do Brasil, Região Sudeste, Rio de Janeiro. IBGE.

Motoyama, S. - 1977 - Sobre o modelo lógico do desenvolvimento científico. Métodos em Questão. São Paulo. Instituto de Geografia - USP, (15):1-47. .

Nascimento, S.A.M. - 1986 - Mapa Pedogeoquímico do Estado da Bahia. 1:1.000.000. Secretaria das Minas e Energia. Superintendência de Geologia e Recursos Minerais.

Novaes Pinto, M. - 1988 - Aplainamento nos trópicos - uma revisão conceitual. Geografia. Rio Claro, 13(26):119-129.

Parizzi, M.G. - 1993 -A gênese e a dinâmica da Lagoa Santa, com base em estudos palinológicos, geomorfológicos e geológicos de sua bacia. Belo Horizonte. Departamento de Geologia, IGC-UFMG. pp 60.

Parizzi, M.G, \& Kohler, H.C. \& SalgadoLaboriau, M.L. - 1996 - A história evolutiva da Lagoas Santa - MG, reveladas através de análises geomorfológicas e palinológicas. Anais XXXIX Congresso Brasileiro de Geologia. SBG. Vol. 1:486-488.

Parizzi, M.G. \& Salgado-Laboriau,M.L. \& Kohler, H.C. - 1998 - Genesis and environmental history of Lagoa Santa, southeastern Brazil. The Holocene 8 (3):311-321.

Queiroz Neto, J.P. \& Journaux, A. (coord.) 1978a - Memorial explicativo da carta geomor-fológica do vale do Rio do Peixe em Marília - SP. Sedimentologia e Pedologia. São Paulo. Instituto de Geografia - USP, (10): 1-22.

Queiroz Neto, J.P. \& Journaux, A. - 1978 b Memorial explicativo da carta geomorfológica. de São Pedro-SP. Sedimentologia e Pedologia. São Paulo. Instituto de Geografia - USP, (12):1-33.

Queiroz Neto, J.P. \& Journaux, A. - 1978 c Memorial explicativo da carta do modelado e das formações superficiais do médio vale do Rio Parateí - SP. Sedimentologia e Pedologia. São Paulo. Instituto de Geografia - USP, (9):1-35.

Ross, J.L.S. - 1992 - 0 registro cartográfico dos fatos geomórficos e a questão da taxonomia do relevo. Revista Departamento de Geografia. São Paulo. FFLCU-USP, (6).

Ruellan, A. \& Dosso.M. \& Fritsch,E. - 1989 L'analyse structurale de la coberture pédologique. Science. 27(4):319-334.

Salomão, F.X.T. - 1994 - Processos erosivos lineares em Bauru, SP: regionalização cartográfica aplicada ao controle preven- 
tivo urbano e rural. São Paulo Dep. De Geografia, FFLCH-USP. (tese doutorado) p. 104.

Schobenhaus, C. - 1984 - Geologia do Brasil. DNPM, pp501.

Schumm, S. A. - 1985 - Explanation and extrapolation in Geomorphology: seven reasons for deologyc uncertainty. Transactions. Japanese Geomorphological Union 6(1): $1-18$.

Silva, T.C. - 1984 - Bibliografia em geomorfologia. CTG, Sociedade Brasileira de Geologia. Rio de Janeiro, 110 p.

Silva, T.C. (Coord.) - 1980 - Mapa Geomorfológico do Estado da Bahia. 1:1.000.000, CEPLAB, Secretaria de Planejamento, Ciência e Tecnologia.

Soctchava, V. B. - 1972 - Por uma teoria de classificação de geossistemas. de vida terrestre. Biogeografía. São Paulo. Instituto de Geo-grafia - USP. São Paulo,(14)1-24.

Soctchava, V.B. - 1977 - 0 estudo de geossistemas. Métodos em Questão. Instituto de Geografia USP. São Paulo, (16):1-52.

Spoenemann, J. \& Lehrmeier, F. - 1989 Geomorphologische Kartierung in. der Bundesrepublik Deutschland: Normung und Weiterentwicklung. Erdkunde. 43(2):77-86.

Thomas, M.F. - 1994- Geomorphology in the tropics. New York. John Wiley \& Sons. pp 460.

Thomas, M.F. - 1974 - Tropical Geomorphology.London. Macmillan.

Thomas, M. F. - 1968 - Etchplain. In FAIRBRIDGE, R. W. Encyclopaedia of Geomorphology, New York. Reinhold. Pp.331-333. 